\title{
Özofagus kanserleri tedavisinde minimal invaziv cerrahi uygulamaları
}

\author{
Minimally invasive surgery modalities in the treatment of esophagial cancers
}

\author{
Hasan Fevzi Batırel*, H.Volkan Kara
}

Marmara Üniversitesi, Tıp Fakültesi, Göğüs Cerrahisi Anabilim Dall, İstanbul, Türkiye

\begin{tabular}{ll}
\hline MAKALE BÍLGILERİ \\
\hline Makale geçmişi \\
\begin{tabular}{ll} 
Geliş tarihi & $: 26 / 09 / 2012$ \\
Kabul tarihi & $: 26 / 10 / 2012$ \\
\hline
\end{tabular} \\
\hline
\end{tabular}

\section{* Yazışma Adresi:}

Hasan Fevzi Batırel

T.C Sağlık Bakanlığı,

Marmara Üniversitesi Tıp Fakültesi,

Pendik Eğitim Araştırma Hastanesi,

Gögüs Cerrahisi Anabilim Dalı,

Pendik, İstanbul

e-posta: hbatirel@marmara.edu.tr

\section{Anahtar Kelimeler:}

Özofagus kanseri

Minimal invaziv cerrahi

Tedavi

\section{Keywords:}

Esophagial cancer

Minimally invasive surgery

Treatment

\section{ÖZET}

Özofagus kanserleri toplumda giderek daha sık görülen yüksek mortaliteyle seyreden bir hastalıktır. Cerrahi özofagus kanserlerinin ilk üç evresinde en önemli tedavi yöntemidir. Açık yapılan özofagus kanser mortalite ve morbidite oranları sırasıyla \% 5-15 ve \% 3060 arasında değişmektedir. Bu yüksek mortalite ve morbidite nedeniyle minimal invazif cerrahi (MİC) önem kazanmıştır. Özofagus kanseri için uygulanan MİC'de hasta seçimi çok önemlidir. Bu yöntemler orta-distal özofagusta yer alan, çevreye invazyonu veya yaygın lenf nodu metastazı bulunmayan evre T1-3 N0-1 tümörlerde uygulanabilir. MİC'de lateral dekübitus pozisyon kullanılabildiği gibi, yüz üstü pozisyonda kullanılmaktadır. MİC ile açık özofajektomi sonuçlarını kıyaslayan randomize kontrollü bir çalışma henüz yoktur, ancak mevcut retrospektif vaka serilerinden çıkan sonuçlara göre MİC'nin onkolojik sonuçlar açısından konvasiyonel özofajektomiye benzer, postoperatif komplikasyonlar açısından ise daha iyi sonuçlara sahip olduğu belirtilmektedir. Halihazırda özofagus kanserinde MİC ciddi deneyime sahip ekipler tarafından uygulanmaktadır. MİC girişim becerilerinin ve alt yapıların geliştirilmesi ile daha sık uygulanabilecektir J. Exp. Clin. Med., 2012; 29:S251-S256

\begin{abstract}
Malignant tumours of esophagus have an increasing frequency in the population with a high mortality. Surgery is the most important choice of treatment modality in the first 3 stages of the disease. In the open surgery methods for esophagial cancers, mortality and morbidity rates are between $5-15 \%$ and $30-60 \%$ respectively. Due to these high rates for mortality and morbidity, minimally invasive surgery (MIS) gained great importance in the treatment of these patients. Patient selection in esophagial cancer treatment by using MIS is very important. These modalities can be used for lesions located in middle-distal portion of esophagus. Tumours should not have any invasion to adjacent structures, widespread lymph node invasions and should be staged between T1-3 N0-1. Lateral decubitus and also prone position can be used for MIS. There are still no controlled randomised studies comparing MIS to open surgery for esophagial cancers. But retrospective series show that oncologic results are similar and postoperative complications are better in MIS groups. On the current daily practice MIS are done by experienced institutuions and surgical groups. In the future MIS will be used more commonly in treatment of esophagial cancers by improvement in invasive skills and infrastructures in the institutions.
\end{abstract}

J. Exp. Clin. Med., 2012; 29: S251-S256

(C) 2012 OMU

\section{Tarihçe}

Özofagus kanseri toplumda giderek daha sık görülen bir hastalık olup, \% 90'a yakın mortalite oranına sahiptir. Cerrahi özofagus kanseri tedavisinde başlıca tedavi tercihlerden biridir (Ng ve ark., 2007; Mehran, 2008). Kanser için uygulanan özofagus rezeksiyonlarında açık yöntem uygulandığında göğüs kafesi ve abdomenin açılmasına bağlı olarak hastalarda yüksek mortalite ve morbidite oranları görülmektedir ( $\mathrm{Ng}$ ve ark., 2007). 1980 yılında Earlam ve Cunhamelo tarafindan yapılan derlemede açık cerrahiyle yapılan özofajektomi ameliyatları için \% 29 mortalite bildirilmiştir (Earlam ve CunhaMelo, 1980). Hatta 2010 yılında yayınlanan makalede İngiliz hastanelerinde yapılan özofajektomilerde genel mortalite oran1 \% 11 olarak bulunmuştur. Bununla beraber yoğun bakım 
imkânlarının iyileşmesi ve cerrahi teknikteki ilerlemelerle birlikte mortalite oranları zaman içerisinde \% 5'e inmiştir. Bu oranları daha da aşağıya çekebilmek için özofagus kanseri tedavisinde yapılan cerrahi girişimlerde minimal invazif cerrahi (MİC) morbidite ve mortalite oranlarının iyileşmesi açısından ümit vaat etmektedir (Ng ve ark., 2007).

Özofagusun büyük bir kısmı anatomik olarak intratorasik yerleşimlidir. Bu nedenle özofagus patolojilerine yönelik girişimler sıklıkla torasik yaklaşım gerektirir. Özellikle özofagus kanserine bağlı rezeksiyonlarında (transhiyatal özofajektomi hariç diğer tüm cerrahi yöntemlerde) özofagusun transtorasik serbestleştirilmesi gerekmektedir. Özofagus cerrahisinde uygulanan transtorasik girişimler sonrasında en sık görülen komplikasyonlar pulmoner kökenlidir (Law ve Wong, 2005). Transtorasik özofajektomi sonrası en sık komplikasyon pnömonidir ve bu hastalarda görülen postoperatif ölümlerin \% 55'i pnömoniye ikincil olarak tespit edilmiştir (Law ve ark., 2003; Law ve Wong, 2005). Bu komplikasyonlara yol açan risk faktörleri arasında torakotomi insizyonunun oluşturduğu doğrudan travma, torakotomi sonrası ağriya bağlı hipoventilasyon ve atelektaziler ve cerrahi travmanın büyüklüğü ilk sıralarda gelmektedir. 1989 yılı sonunda ilk laparoskopik kolesistektomi yapılmasını takiben minimal invaziv girişim şekli özofagus cerrahisiyle uğraşan tıp insanlarının da ilgisini çekmiştir. Özofagus cerrahisi sonrası pulmoner komplikasyon oranlarını azaltmak amacıyla, 1990'lı yıllardan itibaren minimal invaziv yöntemler kullanımaya başlamıştır. 1991'de Dallemagne ilk laparoskopik fundoplikasyonu, 1993'de Azagra ve Gossot ilk torakoskopik özofagus serbestleştirmesini yapmışlar ve yayınlamışlardır (Azagra ve ark., 1993; Gossot ve ark., 1993). Takip eden yıllarda laparoskopik cerrahi girişimler özofagusun benign hastalıkları için geniş oranda kabul ve aynı şekilde uygulama görmüşken, özofagus kanserinde bu durum daha yavaş ilerlemiştir. Çeşitli merkezlerden az sayıda minimal invaziv girişim yapılan özofagus kanseri vakaları rapor edilirken, 2003 yılında Luketich ve arkadaşları 222 hastalık torakoskopik-laparoskopik özofajektomi serilerini yayınlamışlardır (Luketich ve ark., 2003). Hâlihazırda özofagus kanserinde MIC önemlidir, ama standart hale gelmemiştir. Bunun nedeni uygulanan özofajektomi yöntemlerinin çok farklı ve cerrahın tecrübesinin teknik başarı açısından önemli olmasıdır. Ayrıca yöntem başlangıçta teknik olarak uzun sürmekte, zaman ve sabır gerektirmektedir. MİC'i açık yöntemle karşılaştıran bazı çalışmalar halen devam etmektedir (Mehran, 2008).

\section{Hasta seçimi, hazırlığı ve teknik ekipman}

Minimal invazif cerrahide uygun hasta çok önemlidir. Hastalar sıfır performans statüsünde olmalı, kardiak ve pulmoner rezervleri yeterli olmalıdır. Daha önce geçirilmiş toraks ya da abdomen kökenli major cerrahi girişimlerin MİC denemelerini karmaşık ve zor hale getirebileceği unutulmamal1dır (Earlam ve Cunha-Melo, 1980; Mehran, 2008). Özofagus tümörün evresi cerrahinin açık ya da minimal invazif olacağı konusunda belirleyicidir. MİC daha çok orta, distal özofagusta yer alan, yaygın metastatik lenf bezleri bulunmayan Evre T1-3 N0-1 tümörler için kullanılabilir. Daha ileri evredeki tümörler ya da özofagus etrafındaki yapılara invazyon, çölyak lenf nodlarına yayılım şüphesi gösteren tümörlerin geleneksel açık cerrahi yöntemlerle opere edilmesi daha uygundur (Mehran, 2008). Özofagus kanseri varlığında torakoskopik ameliyatların geçerlilik kazanması için yeterli onkolojik (tam tümör rezeksiyonu ve lenfadenektomi) tedavinin uygulanıyor olması, cerrahi olarak güvenli bir şekilde yapılabilmesi açık yöntemlerle kıyaslanması gereken ana kriterlerdir. 15 ülkeden 618 cerrah tarafindan cevaplanan anket çalışmasında, özofagus cerrahisinde minimal invaziv yöntemlerin daha sıklıkla akademik merkezlerde çalışan ve yüksek sayıda (>15 ameliyat/yıl) özofajektomi yapan cerrahlar tarafından tercih edildiği gösterilmiştir (Enestvedt ve ark., 2010).

Özofajektomi uygulanacak vakalarda kolon temizliğini rutin olarak yapan klinikler olmakla beraber 12 saatlik açlik süresinin de yeterli olduğu kabul görmüş bir fikirdir. Hastaya cerrahi başlamadan özofagoskopi ve bronkoskopi yapılmalıdır ve bu işlemleri takiben çift lümenli endotrakeal tüp yerleştirilir. Lateral dekübitus pozisyonunda yapılacak tüm vakalarda çift lümenli endotrakeal tüp uygulanması gereklidir. Palanivelu ve ark. yüz üstü pozisyonda torasik özofagus cerrahisinin daha kolay olduğunu, çift lümenli endotrakeal tüp yerleştirilmesine ihtiyaç olmadığını belirtmişlerdir. Ekip bu pozisyonda ameliyat ettikleri 130 hastalık seriyi yayınlamışlardır (Palanivelu ve ark., 2006). Bununla beraber yüzüstü serbestleştirme sırasında torakotomiye ihtiyaç duyulduğu durumlarda hastaya tekrar pozisyon verilmesi gerekeceği unutulmamalıdır. Torakoskopik özofagus serbesteştirmesi için kullanılan standart insizyonlar, kamera için 6. interkostal aralık ön aksiller hat $(2 \mathrm{~cm})$, traksiyon ve alet yerleştirmek için 4. interkostal aralık ön aksiller hat $(2 \mathrm{~cm})$ ve 4 . interkostal aralık skapula ucunun posterosüperioru $(1 \mathrm{~cm})$ ve kesici aletleri kullanmak için 8. interkostal aralık posterior aksiller hat $(1 \mathrm{~cm})$ üzerine yapılır (Şek. 1).

Özofagusa yönelik torakoskopik girişimlerinin tamamında 30 derecelik lens kullanmak gerekir. Otuz derecelik lens ile toraksın tamamı rahatlıkla görüntülenebilir. Cerrahın hastanın anteriorunda olması uygulamada belirgin kolaylık sağlar, bu şekilde hasta anterioruna doğru 30 derece döndürülebilir ve böylece posterior mediyasten daha kolay görülür ve akciğer anteriora doğru düşer. Posteroinferior mediyasteni daha rahat görüntüleyebilmek için diyaframın santral tendonuna kalın bir askı dikişi konulabilir ve ipler kamera portundan çıkarılarak traksiyon uygulanabilir. Torakoskopik uygulamalarda kullanılan makas, klemp, dissektör veya büyük ve küçük dik açılı klempler gibi standart aletlerin yanı sıra açık cerrahide kullanılan uzun $(>30 \mathrm{~cm})$ aletler de tercih edilebilir. Damarları bağlamak için ultrasonik kesici veya elektrotermal bipolar damar kapatıcılar kullanılabilir, yine de küçük ve orta boy torakoskopik kliplerin de hazırda olması önemli ve gereklidir. Ayrıca özofagus serbestleştirmesi uygulanacak vakalarda azigosun kesilebilmesi için 30-35 mm' lik endoskopik vasküler staplerların kullanılması muhtemeldir. Özofagusu askıya almak için kalın lastikten 2,5 cm' lik penröz dren kullanılabilir. Ayrıca aspirasyon-irrigasyon sistemi ve küçük ve büyük gazlı bezlerden yapılan tamponlar kanama kontrolü ve ekartasyon için kullanılabilir. "Endoskopik fındık tampon" olarak adlandırılan uzun sopaların ucuna yerleştirilmiş yuvarlatılmış spançlar da diseksiyon için sıklıkla kullanılmaktadır.

\section{Cerrahi teknikler ve sonuçları}

Özofagusta torakoskopi genellikle özofajektominin bir aşaması olarak uygulanır. Özofajektomi operasyonu değerlendirildiğinde torakoskopinin uygulandığı üç durum mevcuttur. 


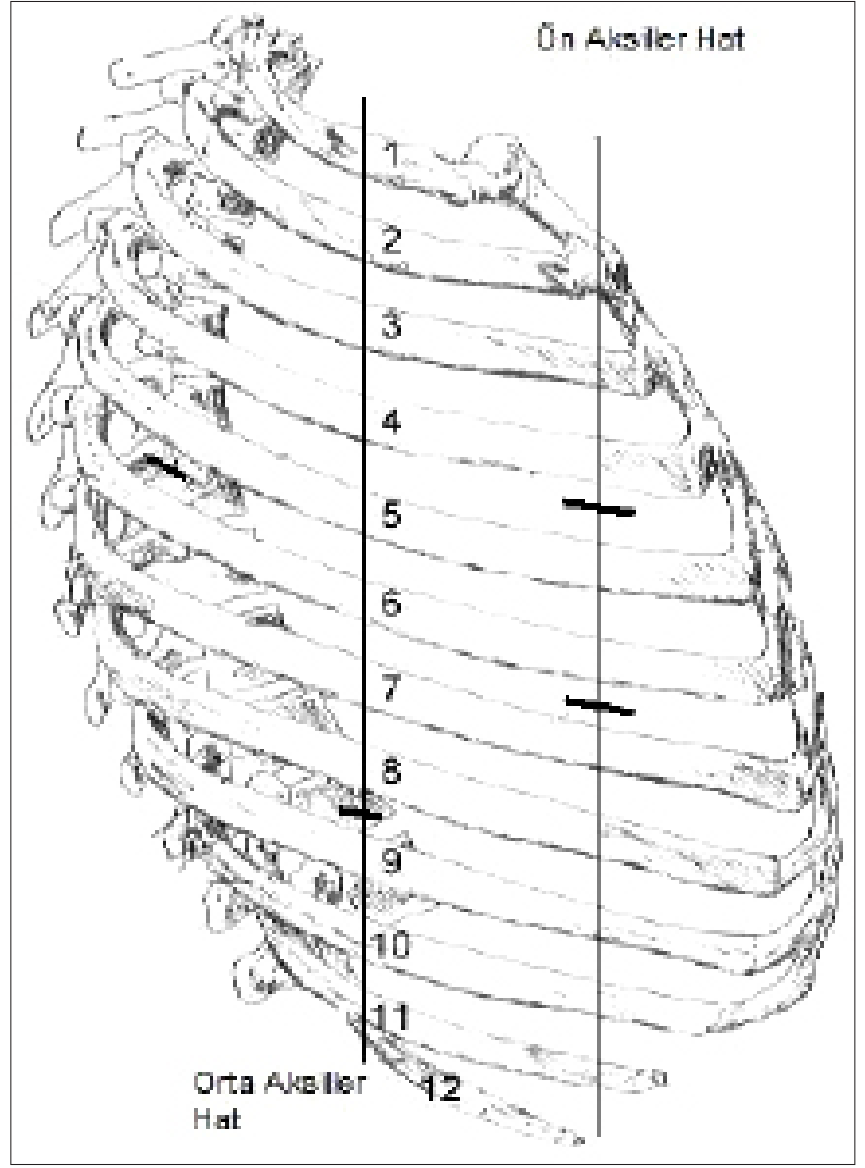

Şek. 1. Torakoskopik özofagus serbesteştirmesi için kullanılan standart insizyonlar: Kamera 6. İnterkostal aralık ön aksiller hat $(2 \mathrm{~cm})$; traksiyon ve alet yerleştirmek için 4 . İnterkostal aralık ön aksiller hat $(3 \mathrm{~cm})$; traksiyon ve manipülasyon için 5. İnterkostal aralık skapula ucunun posteriorsüperioru $(2$ $\mathrm{cm}$ ) ve kesici aletleri kullanmak için 8. İnterkostal aralık posterior aksiller hat $(1 \mathrm{~cm})$.

1.Torakoskopik özofagus serbestleştirmesi + laparotomi + sol servikal insizyon ile totale yakın özofajektomi

2. Torakoskopik özofagus serbestleştirmesi + laparoskopik mide tübülarizasyonu + sol servikal insizyon ile totale yakın özofajektomi

3.Laparoskopik veya laparotomi ile mide tübülarizasyo$\mathrm{nu}+$ Sağ torakoskopi ile Ivor-Lewis özofajektomi

\section{Torakoskopik özofagus serbestleștirmesi}

Özofagusun torakoskopik serbestleştirmesi için hasta hazırlığı ve teknik ekipman bölümünde belirtilen uygulamalar yapılır. Anterior 4. interkostal aralıktaki insizyon kullanılarak mediastinal plevra intermedier bronş ve inferior pulmoner venin posteriorundan açılır. Posteriorda azigos ven önüne ge

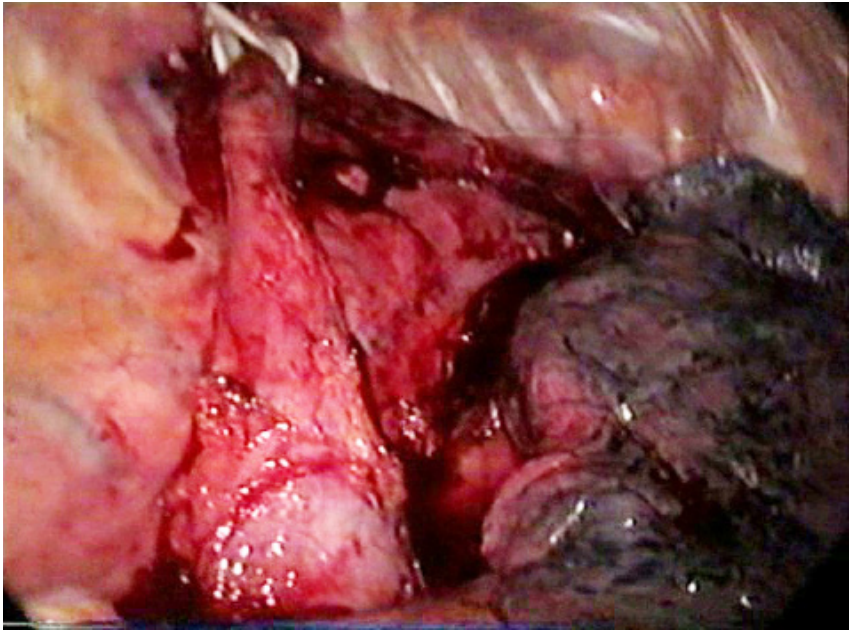

Şek. 2. Torakoskopik olarak torasik girişte serbestleştirilmiş özofagus görülmektedir.

lecek şekilde mediastinal plevra açılır. İlk serbestleştirmenin mümkünse tümörün primer lokasyonundan uzak kalacak şekilde yapılması özofagusun doğru planda askıya alınmasını sağlayacaktır. Posteriorda torasik duktusu spesimen içerisine alıp almamak cerrahın onkolojik tercihidir. Özofagus posteriorda aorta ve anteriorda perikard ve intermedier bronş üzerinden serbestleştirilerek askıya alınır. Özofagus subkarinal, paraözofajiyal, pulmoner ligaman lenf bezleriyle birlikte en blok olarak serbestleştirilir. Takiben azigos ven kesilir. Reküren larinjeal sinir hasarını önlemek amacıyla azigos venin üzerinde özofagus duvarına yakın diseksiyon yapılır. Toraks girişinden hiatusa kadar tüm özofagus serbestleştirilir (Şek. 2).

Ayrıca sağ reküren larinjeal ve sağ paratrakeal lenf bezlerinin de örneklenmesi doğru evreleme açısından önemlidir. Kanama kontrolünün ardından toraksa tek dren konularak işleme son verilir.

Torakoskopik özofagus mobilizasyonu ile özofajektomi uygulanan değişik serilerdeki vaka sayıları, mortalite, pnömoni, açığa geçme oranları, hastanede kalış süreleri ve ç1karılan lenf nodu sayıları Tablo 1'de gösterilmiștir (Dexter ve ark., 1996; Smithers ve ark., 2001; Osugi ve ark., 2003; Yamamoto ve ark., 2005; Palanivelu ve ark., 2006; Smithers ve ark., 2007; Zhou ve ark., 2009).

Tablodan da görüleceği ve diğer serilerde de belirtildiği üzere hastalarda ortaya çıkan pnömoni oranları bazı serilerde açık özofajektomi ile aynıdır. Bunun nedeni olarak başlangıçtaki öğrenme sürecine bağlı olarak uzun ameliyat süreleri ve tek akciğer ventilasyonu süresinin uzun tutulması öne sürülmüştür (Decker ve ark., 2009). Nitekim torakoskopik laparoskopik özofajektomi uygulanan Luketich'in 222 vakalık

\begin{tabular}{|c|c|c|c|c|c|c|c|}
\hline Yazar & Yayın yılı & Hasta sayısı & Mortalite (\% ) & Pnömoni (\% ) & Açığa Geçme & HKS (gün) & LN Sayısı \\
\hline Petri & 2011 & 40 & 4,4 & 15,2 & 0 & 15 & 13 \\
\hline Zhou & 2009 & 30 & 0 & 7 & 0 & 17 & $26 \pm 5$ \\
\hline Smithers & 2007 & 309 & 2,3 & 26 & - & 13 & 17 \\
\hline Palanivelu* & 2006 & 130 & 1,5 & 2 & 0 & 8 & 18 \\
\hline Yamamoto & 2005 & 112 & 1,8 & 6 & $1 / 112$ & - & 28 \\
\hline Osugi & 2003 & 80 & 0 & 16 & 16 & 0 & $34 \pm 12$ \\
\hline Smithers & 2001 & 162 & 5,3 & 27 & 27 & $11 / 162$ & $11 \pm 8$ \\
\hline Dexter & 1996 & 24 & 12 & - & - & 0 & 13 \\
\hline
\end{tabular}

HKS, Hastanede kalış süresi; LN, lenf nodu.

* Yüzüstü pozisyonda torakoskopik serbestleştirme uygulanmıştır 
serisinde pnömoni oranı $\% 8$, bronkoskopi gerektiren atelektazi oranı \% 4,5'tur (Luketich ve ark., 2003). Özofajektomi sonrası görülen reküren larinjeal sinir hasarı ve anastomoz kaçağı oranları açık cerrahi yöntemlerle benzerdir (Decker ve ark., 2009). Bununla beraber torakoskopik özofagus mobilizasyonu serilerde şimdiye kadar 15 trakeal nekroz vakası bildirilmiştir (Decker ve ark., 2009). Oysa açık cerrahi yöntemde bu oran sıfıra yakındır. Trakeal nekrozun özellikle kullanılan ultrasonik kesici veya bipolar damar kapatıcılarının trakeaya çok yakın kullanılmasından ve kollateral ısı hasarından kaynaklanabileceği iddia edilmiştir.

Torakoskopik serbestleştirmenin yüzüstü veya lateral dekübit pozisyonunda yapılmasına yönelik karşılaştırmalı çalışmada çıkarılan lenf nodu sayısı, komplikasyonlar, hastanede kalış süresi, ameliyat sırasındaki kan kaybı açısından bir fark bulunamazken, ameliyat süresi yüzüstü pozisyonda anlamlı olarak kısa bulunmuştur (Fabian ve ark., 2008). Faringolaringo özofajektominin bir aşaması olarak torakoskopik mobilizasyon transhiyatal mobilizasyon ile karşılaştırılmış ve komplikasyonlar ve mortalite açısından bir fark bulunamamıştır (Lawve ark., 2000). Bununla beraber bir başka çalışmada aynı klinikte değişik zaman süreçlerinde torakoskopiklaparoskopik özofajektomi uygulanan ardışı 50 vaka, Ivor Lewis özofajektomi uygulanan 30 vaka ile karşılaştırılmış ve pnömoni oranları sırasıyla $\% 8$ ve $\% 23$ olarak hesaplanmıştır (Parameswaran ve ark., 2009). 2009 yılında yapılan metaanalizde torakoskopik serbestleştirme uygulanan vakalarda kaçak oranının anlamlı olarak düşük olduğu pulmoner ve diğer komplikasyonlar ve mortalite açısından bir fark olmadığı ortaya konmuştur (Biere ve ark., 2009). Bununla beraber açık özofajektomi uygulanan 98 vaka ile minimal invaziv cerrahi ile özofajektomi uygulanan 56 vaka karşılaştırıldığında, torasik epidural analjezi uygulanan vakalarda MIC yöntemle mortalite oranlarında \% 75 düşme sağlandığ (Braghetto ve ark., 2006). Bir başka çalışmada, pulmoner komplikasyonlar arasında bir fark olmaması, özofagus serbestleştirmesi sırasında farenks ve larenksin denervasyonuna ve buna bağlı aspirasyon riskine bağlanmıştır (Atkins ve ark., 2003). Postoperatif erken dönemde videofloroskopik kontrastlı çalışma yapılan 4 hastanın 3'ünde aspirasyon tespit edilmiş ve 2 'sinde pulmoner komplikasyonlar gelişmiştir (Atkins ve ark., 2003).

\section{Torakoskopik Ivor-Lewis özofajektomi}

Servikal anastomoz uygulanan özofajektomilerde anastomotik kaçak ve darlık oranlarının yüksek olması (sırasıyla; > $\% 10$ ve $>\% 25$ ), cerrahların tekrar Ivor Lewis özofajektomiyi tercih etmelerine neden olmaktadır (Swanson ve ark., 2001; Orringer ve ark., 2007). Ivor Lewis özofajektominin laparoskopik ve torakoskopik olarak klinik pratikte uygulanabilir hale gelmesi son yıllarda mümkün olmuştur. Nitekim bu konudaki ilk makale 2006 yılında yayınlanmıştır (Bizekis ve ark., 2006). Torakoskopik-laparoskopik Ivor Lewis özofajek- tomide cerrahi sonuçlar Tablo 2'de gösterilmiştir (Bizekis ve ark., 2006; Nguyen ve ark., 2008; Hamouda ve ark., 2010).

Minimal invaziv Ivor-Lewis özofajektomi kardiya tümörü olan bazı vakalarda ve iatrojenik distal özofagus perforasyonunda dahi uygulanmıştır (Grewal ve ark., 2009; Hinojosa ve ark., 2009).

Laparoskopi veya laparotomi ile mide konduitinin hazırlanmasını ve çıkarılacak kısma dikilmesini takiben torakoskopik özofagus mobilizasyonu lateral dekübitus pozisyonunda yukarıda belirtilen şekilde yapılır. Mide toraks içerisine çekildikten sonra özofagus torasik giriş kısmından kesilir ve spesimen bir torbaya yerleştirilerek çıkarılır. Sirküler stapler kullanılarak proksimal özofagus ile mide konduitinin anastomozu gerçekleştirilir. Sirküler stapler 6. interkostal aralık posterior aksiller hat üzerine yapılan $5 \mathrm{~cm}$ ' lik yardımcı insizyondan yerleştirilebileceği gibi, bazı yazarlar transoral yerleştirilebileceğini de göstermişlerdir (Nguyen ve ark., 2008). Anastomozun tamamlanmasını takiben midedeki insizyon stapler veya endoskopik dikişlerle kapatılır. Toraksa bir adet silikon toraks dreni ve anastomoz etrafina ince vakumlu dren yerleştirilir.

Anastomoz kaçağı özofagus rezeksiyonları sonrası hayati tehlike oluşturabilecek postoperatif komplikasyonlardan biridir. Bozulan mikro dolaşımın bu konuda belirgin şekilde rol oynadığı düşünülmektedir (Hoppo ve ark., 2011). Bu komplikasyonu engellemek için arteriyal kan akışını özellikle de kondulit ucuna arttırmaya yönelik yöntemler araştırılmaktadır. Preoperatif dönemde laparoskopik sol gastrik arterin bağlanması sonucu oluşturulan gastrik iskemik durum (ki bu işlem sayesinde laparoskopik evrelendirmede yapılmış olmaktadır) gastrik kondilitte özofajektomi zamanına dek neovaskülarizasyon oluşturmayı sağlamakta ,bu özellikle neoadjuvan tedavi almış hastalarda artmış kaçak oluşma ihtimalini düşürmektedir (Hölscher ve ark., 2007; Varela ve ark., 2008). Bu yaklaşıma benzer bir diğer uygulama da preoperatif anjiografik sol gastrik, distal sağ gastrik ve splenik arter embolizasyonlarıdır bu yaklaşımda özofajektomi öncesi benzer iskemi ye bağlı neovaskülarizasyon durumu oluşturulabilmektedir (Akiyama ve ark., 1998). Omentumun kondüit üzerine örtülerek kondüitin ve anastomoz hattının güçlendirilmesi kaçak oranını azaltmakta, ilaveten işleme bağlı morbidite ve mortalite oranını da düşürmektedir (Bhat ve ark., 2006).

\section{Gelecekten beklentiler}

Özofagus cerrahisinde robotik yöntemler son yıllarda daha sık kullanılmaya başlanmıştır. Özofagusun torakoskopik mobilizasyonun robotik yöntemler kullanılarak yapıldığg vakalar literatürde bildirilmiştir (Dapri ve ark., 2006). Robotik cerrahinin katkısı cerrahi görüntünün üç boyutlu ve cerrahın el hareketlerinin çok rahat olmasıdır (Watson, 2008). Özellikle özofagus kanseri cerrahisinde torakoskopik yöntemler lenf nodu diseksiyonuna ve doğrudan görüntü altında özofagus

Tablo 2. Minimal invaziv Ivor-Lewis sonuçları

\begin{tabular}{lccccccc}
\hline Yazar & Yayın yılı & Hasta sayısı & Mortalite (\%) & Pnömoni (\%) & Açı̆̆a Geçme & HKS (gün) & LN Sayısı \\
\hline Tapias & 2011 & 40 & 0 & 3 & 0 & 7 \\
Hamouda & 2009 & 46 & 0 & 30 & 0 & - \\
Nguyen & 2008 & 51 & 217 & 0 & 10 \\
Bizekis & 2006 & 50 & 6 & 8 & 0 & 9 \\
\hline
\end{tabular}

HKS, Hastanede kalıș süresi; LN, lenf nodu 
serbestleştirmesine izin verdiği için transhiyatal yöntemin yerini almaya adaydır. Yüz üstü pozisyonda yapılan özofagus serbestleştirmesinin lateral dekübitus pozisyonuna göre daha kolay ve güvenli olduğuna dair yayınlar bulunmaktadır (Palanivelu ve ark., 2006; Fabian ve ark., 2008). Yine de bu konuda yeni randomize çalışmalara ihtiyaç vardır. Ivor-Lewis özofajektominin minimal invaziv olarak uygulanması durumunda anastomotik kaçak ve striktür oranları açısından sol servikal anastomoz uygulanan yönteme göre daha avantajlı olduğu iddia edilmektedir (Bizekis ve ark., 2006). Ayrıca omentum ile anastomozun sarılmasının kaçak oranını sıfıra indirebileceği tartışılmaktadır.

MíC ile açık özofajektomi sonuçlarını kıyaslayan randomize kontrollü çalışma henüz yoktur, mevcut verilere göre MíC nin konvasiyonel özofajektomiye benzer sonuçlara sahip olduğu belirtilmekte ancak daha üstün olduğuna dair bildirim bulunmamaktadır (Earlam ve Cunha-Melo, 1980). $\mathrm{Bu}$ konuda veri birikimi devam etmektedir. Gemmill ve Mc Culloch'nin yaptığı sistematik bir derlemede özofagus kanserinin minimal invazif yöntemlerle rezeke edilen literatürdeki 1300' ü aşkın hastada \% 2,3 mortalite, \% 46,2 morbidite ve \% 7,7 kaçak oranı hesaplanmıştır. Ortalama hastane kalış süresi 11 gündür. $\mathrm{Bu}$ değerler açık cerrahiyle benzerdir (Gemmill ve McCulloch, 2007). Biere ve ark. yaptıkları meta analizde minimal invazif grupta azalmış mortalite oranına bir miktar meyil izlense de açık ve minimal invazif yöntemler arasında major morbidite ve mortalite oranlarında belirgin fark görülmemiştir (Biere ve ark., 2009). Diğer bir metaanalizde MİC daha az kan kaybı, kısalmış operasyon süresi ve hastane yatışı ve daha düşük oranlı pulmoner komplikasyonları göstermektedir (Nagpal ve ark., 2010). Açık cerrahiyle MíC kıyaslamasının yapılabilmesi için çok merkezli prospektif randomize kontrollü çalışmalara ihtiyaç vardır.

Özofajektomi tüm gastrointestinal cerrahi işlemler gru- bunda en komplike ve teknik olarak en zor işlemlerdir. Sonuçlar merkezin hasta yükü, cerrahın ve merkezin işlem tecrübesiyle direkt bağlantılıdır (Hoppo ve ark., 2011). MIC teknikleri ve hasta yönetim süreçleri hakkında mevcut bilgi birikimleri MİC nin açık cerrahiye göre daha üstün sonuçlar üreteceği düşünülmektedir.

\section{Sonuç}

Özofagus neoplazilerine yönelik rezeksiyonlarında minimal invazif yöntemler güvenli ve uygulanabilirdir. Mevcut kısıtlı verilere göre MİC'nin kısa dönem sonuçları daha başarılı olarak net tanımlanamasa da açık yöntemlerle kıyaslanabilir durumdadır (Mehran, 2008). Bu süreçte cerrahi yapılan sahanın büyütülmüş görüntüsüyle işlemler pratikleşmektedir. Onkolojik cerrahinin temel prensipleri olan tümör ve etkilemesi beklenen lenf nodu alanlarının komplet rezeksiyonunun sürece sağladığı olumlu ve daha ölçülebilir başarılı sonuçlar bu uygulamaların geleceğini diğer sistem örneklerinde (abdomen cerrahisi) olduğu gibi olumlu işaret etmektedir. Torakoskopik cerrahinin daha az ağrı ve inflamatuar cevap, hastanede kalış süresinin kısalması, kas gücünün korunması ve erken işe dönme gibi avantajları özofagus cerrahisinde de geçerlidir. Özofagus kanser cerrahisinde torakoskopik serbestleştirme komplikasyon oranlarını değiştirmemekle beraber, postoperatif mortalite ve hayat kalitesi açısından daha avantajlı görünmektedir. MíC konusundaki veriler yüksek hasta yüküne sahip merkezlerde dahi farklılıklar gösterebilmektedir. Mevcut durumda bu MİC, konu ve işleyiş hakkında ciddi deneyime sahip ekipleri barındıran merkezler tarafından uygulanmalıdır. Minimal invazif cerrahi girişim becerilerinin ve alt yapıların geliştirilmesi özofagus kanserlerinde uygulanan MíC başarı oranlarını da arttıracaktır. İlave çalışmalar MIC etkinliği ve onkolojik açıdan uzun dönem sonuçların tespiti açısından gerekmektedir.

\section{KAYNAKLAR}

Akiyama, S., Kodera, Y., Sekiguchi, H., Kasai, Y., Kondo, K., Ito, K., Takagi, H., 1998. Preoperative embolization therapy for esophageal operation. J. Surg. Oncol. 69, 219-223.

Atkins, B.Z., Fortes, D.L., Watkins, K.T., 2007. Analysis of respiratory complications after minimally invasive esophagectomy: Preliminary observation of persistent aspiration risk. Dysphagia. 22, 49-54.

Azagra, J.S., Ceuterick, M., Goergen, M., Jacobs, D., Gilbart, E., Zaouk, G., Carlier, E., Lejeune, P., Alle, J.L., Mathys, M., 1993. Thoracoscopy in oesophagectomy for oesophageal cancer. Br. J. Surg. 80, 320-321.

Bhat, M.A., Dar, M.A., Lone, G.N., Dar, A.M., 2006. Use of pedicled omentum in esophagogastric anastomosis for prevention of anastomotic leak. Ann. Thorac. Surg. 82, 1857-1862.

Biere, S.S., Cuesta, M.A., van der Peet, D.L., 2009. Minimally invasive versus open esophagectomy for cancer: A systematic review and metaanalysis. Minerva Chir. 64, 121-133.

Bizekis, C., Kent M.S., Luketich, J.D., Buenaventura, P.O., Landreneau, R.J., Schuchert, M.J., Alvelo-Rivera, M., 2006. Initial experience with minimally invasive Ivor Lewis esophagectomy. Ann. Thorac. Surg. 82, 406-407.

Braghetto, I., Csendes, A., Cardemil, G., Burdiles, P., Korn, O., Valladares, H., 2006. Open transthoracic or transhiatal esophagectomy versus minimally invasive esophagectomy in terms of morbidity, mortality and survival. Surg. Endosc. 20, 1681-1686.

Dallemagne, B., Weerts, J.M., Jehaes, C., Markiewicz, S., Lombard, R., 1991. Laparoscopic Nissen fundoplication: Preliminary report Surg. Laparosc. Endosc. 1, 138-143.

Dapri, G., Himpens, J., Cadière, G.B., 2006. Robot-assisted thoracoscopic esophagectomy with the patient in the prone position.J Laparoendosc Adv Surg Tech A. 16, 278-285.

Decker, G., Coosemans, W., De Leyn, P., Decaluwé, H., Nafteux, P., Van Raemdonck, D., Lerut, T., 2009. Minimally invasive esophagectomy for cancer. Eur. J. Cardiothorac. Surg. 35, 13-21.

Dexter, S.P., Martin, I.G., McMahon, M.J., 1996. Radical thoracoscopic esophagectomy for cancer. Surg. Endosc. 10, 147-151.

Earlam, R., Cunha-Melo, J.R., 1980. Oesophageal squamous cell carcinoma: I. A critical review of surgery. Br. J. Surg. 67, 381-390.

Enestvedt, C.K., Perry, K.A., Kim, C., McConnell, P.W., Diggs, B.S., Vernon, A., O’Rourke, R.W., Luketich, J.D., Hunter, J.G., Jobe, B.A., 2010. Trends in the management of esophageal carcinoma based on provider volume: Treatment practices of 618 esophageal surgeons. Dis. Esophagus. 23, 136-144.

Fabian, T., Martin, J., Katigbak, M., McKelvey, A.A., Federico, J.A., 2008. Thoracoscopic esophageal mobilization during minimally invasive esophagectomy: A head-to-head comparison of prone versus decubitus positions. Surg. Endosc. 22, 2485-2491. 
Gemmill, E.H., McCulloch, P., 2007. Systematic review of minimally invasive resection for gastro-oesophageal cancer. Br. J. Surg. 94, 14611467.

Gossot, D., Fourquier, P., Celerier, M., 1993. Thoracoscopic esophagectomy: Technique and initial results. Ann. Thorac. Surg. 56, 667-670.

Grewal, N., El-Badawi, K., Nguyen, N.T., 2009. Minimally invasive ivor lewis esophagectomy for the management of iatrogenic esophageal perforation in a patient with esophageal cancer. Surg. Technol. Int. 18, 82-85.

Hamouda, A.H., Forshaw, M.J., Tsigritis, K., Jones, G.E., Noorani, A.S., Rohatgi, A., Botha, A.J., 2010. Perioperative outcomes after transition from conventional to minimally invasive Ivor-Lewis esophagectomy in a specialized center. Surg. Endosc. 24, 865-869.

Hinojosa, M.W., Mailey, B.A., Smith, B.R., Reavis, K.M., Nguyen, N.T., 2009. Minimally invasive Ivor-Lewis esophagogastrectomy for gastric cardia cancer. Surg. Endosc. 23, 2656.

Hoppo, T., Jobe, B.A., Hunter, J.G., 2011. Minimally invasive esophagectomy: The evolution and technique of minimally invasive surgery for esophageal cancer. World J. Surg. 35, 1454-1463.

Hölscher, A.H., Schneider, P.M., Gutschow, C., Schröder, W., 2007. Laparoscopic ischemic conditioning of the stomach for esophageal replacement. Ann. Surg. 245, 241-246.

Law, S.Y., Fok, M., Wei, W.I., Lam, L.K., Tung, P.H., Chu, K.M., Wong, J., 2000. Thoracoscopic esophageal mobilization for pharyngolaryngoesophagectomy. Ann. Thorac. Surg. 70, 418-422.

Law, S., Wong, J., 2005. Current management of esophageal cancer. J. Gastrointest. Surg. 9, 291-310.

Law, S., Kwong, D.L., Kwok, K.F., Wong, K.H., Chu, K.M., Sham, J.S., Wong, J., 2003. Improvement in treatment results and long-term survival of patients with esophageal cancer: Impact of chemoradiation and change in treatment strategy. Ann. Surg. 238, 339-348.

Luketich, J.D., Alvelo-Rivera, M., Buenaventura, P.O., Christie, N.A., McCaughan, J.S., Litle, V.R., Schauer, P.R., Close, J.M., Fernando, H.C., 2003. Minimally invasive esophagectomy: Outcomes in 222 patients. Ann. Surg. 238, 486-495.

Mehran, R.J., 2008. Minimally invasive surgical treatment of esophageal carcinoma. Gastrointest. Cancer Res. 2, 283-286.

Nagpal, K., Ahmed, K., Vats, A., Yakoub, D., James, D., Ashrafian, H., Darzi, A., Moorthy, K., Athanasiou, T., 2010. Is minimally invasive surgery beneficial in the management of esophageal cancer? A meta-analysis. Surg. Endosc. 24, 1621-1629.

Ng, C.S., Wan, S., Hui, C.W., Wan, I.Y., Lee, T.W., Underwood, M.J., Yim, A.P., 2007. Video-assisted thoracic surgery lobectomy for lung cancer is associated with less immunochemokine disturbances than thoracotomy. Eur. J. Cardiothorac. Surg. 31, 83-87.

Nguyen, T.N., Hinojosa, M.W., Smith, B.R., Gray, J., Reavis, K.M., 2008. Thoracoscopic construction of an intrathoracic esophagogastric anastomosis using a circular stapler: transoral placement of the anvil. Ann. Thorac. Surg. 86, 989-992.

Nguyen, N.T., Hinojosa, M.W., Smith, B.R., Chang, K.J., Gray, J., Hoyt, D., 2008. Minimally invasive esophagectomy: Lessons learned from 104 operations. Ann. Surg. 248, 1081-1091.

Orringer, M.B., Marshall, B., Chang, A.C., Lee, J., Pickens, A., Lau, C.L., 2007. Two thousand transhiatal esophagectomies: Changing trends, lessons learned. Ann. Surg. 246, 363-374.

Osugi, H., Takemura, M., Higashino, M., Takada, N., Lee, S., Ueno, M., Tanaka, Y., Fukuhara, K., Hashimoto, Y., Fujiwara, Y., Kinoshita, H., 2003. Learning curve of video-assisted thoracoscopic esophagectomy and extensive lymphadenectomy for squamous cell cancer of the thoracic esophagus and results. Surg. Endosc. 17, 515-519.

Palanivelu, C., Prakash, A., Senthilkumar, R., Senthilnathan, P., Parthasarathi, R., Rajan, P.S., Venkatachlam, S., 2006. Minimally invasive esophagectomy: Thoracoscopic mobilization of the esophagus and mediastinal lymphadenectomy in prone position experience of 130 patients. J. Am. Coll Surgeons. 203, 7-16.

Parameswaran, R., Veeramootoo, D., Krishnadas, R., Cooper, M., Berrisford, R., Wajed, S., 2009. Comparative experience of open and minimally invasive esophagogastric resection. World J. Surg. 33, 1868-1875.

Petri, R., Zuccolo, M., Brizzolari, M., Rossit, L., Rosignoli, A., Durastante, V., Petrin, G., De Cecchis, L., Sorrentino, M., 2011. Minimally invasive esophagectomy: Thoracoscopic esophageal mobilization for esophageal cancer with the patient in prone position. Surg. Endosc. 26, 1102-1107.

Smithers, B.M., Gotley, D.C., Martin, I., Thomas, J.M., 2007. Comparison of the outcomes between open and minimally invasive esophagectomy. Ann. Surg. 245, 232-240.

Smithers, BM., Gotley, D.C., McEwan, D., Martin, I., Bessell, J., Doyle, L., 2001. Thoracoscopic mobilization of the esophagus. A 6 year experience. Surg. Endosc. 15, 176-182.

Swanson, S.J., Batirel, H.F., Bueno, R., Jaklitsch, M.T., Lukanich, J.M., Allred, E., Mentzer, S.J., Sugarbaker, D.J., 2001. Transthoracic esophagectomy with radical mediastinal and abdominal lymph node dissection and cervical esophagogastrostomy for esophageal carcinoma. Ann. Thorac. Surg. 72, 1918-1925.

Tapias, L.F., Morse, C.R., 2011. A preliminary experience with minimally invasive Ivor Lewis esophagectomy. Dis. Esophagus. 25,449-455.

Varela, E., Reavis, K.M., Hinojosa, M.W., Nguyen, N., 2008. Laparoscopic gastric ischemic conditioning prior to esophagogastrectomy: Technique and review. Surg. Innov. 15, 132-135.

Watson, T.J., 2008. Robotic esophagectomy: Is it an advance and what is the future? Ann. Thorac. Surg. 85, 757-759.

Yamamoto, S., Kawahara, K., Maekawa, T., Shiraishi, T., Shirakusa, T., 2005. Minimally invasive esophagectomy for stage I and II esophageal cancer. Ann. Thorac. Surg. 80, 2070-2075.

Zhou, J., Chen, H., Lu, J.J., Xiang, J., Zhang, Y., Hu, H., Zhou, X., Luo, X., Yang, F., Tam, J., 2009. Application of a modified McKeown procedure (thoracoscopic esophageal mobilization three-incision esophagectomy) in esophageal cancer surgery: Initial experience with 30 cases. Dis. Esophagus. 22, 687-693. 